\title{
Rebuilding psychiatry in Uganda
}

\author{
Jed Boardman and Emilio Ovuga
}

\begin{abstract}
Psychiatry in Uganda has a fine pedigree. Academic psychiatry was established in the late 1960s when the Makerere University Department of Psychiatry was founded. Academic medicine and psychiatry suffered during the Amin regime but, like the country as a whole, these have begun to rebuild themselves over the past 10 years. Problems still remain including poor facillites, lack of resources, and a need to revise the Mental Treatment Act and standards of treatment. The high prevalence of AIDS and post-traumatic stress disorder place added burdens on Ugandan psychiatry.
\end{abstract}

\section{Uganda}

Uganda, referred to as the 'Pearl of Africa' by Winston Churchill, has an area of $236580 \mathrm{~km}^{2}$ and a population of about 20 million. This beautiful and fertile country varies from semidesert in the north-east to the lush shores of Lake Victoria and the mist covered Rwenzori mountains on its western border. At the time of independence in 1962, Uganda was considered a prosperous and cohesive country but by 1986 it had been damaged beyond recognition due largely to the military tyranny of Idi Amin and successive governments. The country has, however, been steadily rebuilt by a stable regime headed by Yoweri Museveni, who took power in 1986 and was elected president in May 1996. Uganda is more economically and politically stable than it has been for many years, an elected parliament was sworn in during July 1996 and the average annual growth (gross national product per capita) has been $2.3 \%$ between 1985 and 1994. Uganda has been badly hit by AIDS and this has contributed to a reduction in life expectancy for the average Ugandan. The life expectancy for men in Uganda is 42.2 years and for women 44.3, giving the lowest life expectancy in Africa. The literacy rate before the coup of 1971 was $52 \%$ and it now stands at $48 \%$.

\section{Department of Psychiatry, Makerere University}

The history of the Makerere University Medical School in Kampala dates back to 1924, although the current Medical School dates from 1964
(Odonga, 1989). The Makerere University Department of Psychiatry was founded in 1967 and was headed by Allen German. It contained several other British expatriates, including John Orley, Harry Egdell and John Cox, a Canadian, Klaus Minde, and was eight-strong at its peak in 1970-1971. It was initially housed in the Department of Medicine but later moved into its present premises behind the Medical School at Mulago Hospital. Staff development and training were the priorities for the department and several important publications were produced (German \& Arya, 1969; Orley, 1970; Orley \& Wing, 1979; Cox, 1983). Up-country units were established as well as undergraduate and postgraduate training programmes (MMed); at the time the latter was similar in standard to those then available in the UK. With the advent of the Amin regime many departmental members left and the department was weakened. Only one member of the original department remains. The following years were lean and tragic for all academic developments in Uganda.

The department of psychiatry has begun to rebuild itself over recent years (see Table 1) and now has 10 posts, of which three are currently unfilled. Four of the current members are psychiatrists, three are social workers and one a medical sociologist. In spite of able personnel the department is hampered by a poor building and lack of resources. There is no electricity or telephone, few books and no regular supply of journals.

Despite its poor facilities the department is engaged in a busy teaching programme providing teaching for medical students in each of their five years of training, a three year MMedPsych degree for psychiatric trainees, the mental health component of the BSc in Nursing and the Comprehensive Nursing course as well as a course unit for the Masters in Public Health Medicine. Following an absence of 20 years research activity has returned to the department. The findings of one study on stress among nurses in two Kampala Hospitals and the second on traditional healers in Pallisa District were helpful in the development of the curricula of the comprehensive nursing course run by the Ministry of Health and the Masters of Public Health Programme at Makerere University. A study of student mental health has resulted in 
Table 1. Departmental developments

Recent departmental achievements

Staff establishment expanded to include: social scientists, medical sociologist, social worker, clinical psychologist and medical anthropologist

Invitation to be a collaborating centre for the World Mental Health Assembly

World Health Organization collaborative research centre for the conrol of onchocerciasis.

Established collaborative links with the Department of Psychiatry, Keele University

Involved in work to publish educational textbooks in psychiatry in the African sub-region

Plans over the next three years

Establish and develop the sub-specialities of clinical psychology, medical sociology and anthropology, and social work

Solicit funds and grants for training staff in the social sciences field in order to fill vacant posts in the Ministry of Health as well as the University

Develop the research interests and capability of staff both at the department and at Butabika Hospital by engaging postgraduate students of psychiatry

Establish database in mental health research material through involving young doctors in research

Promote the image of mental health and of the department of psychiatry, through regular publications for public consumption. We intend to apply for funding to support the publication of a newsletter or news bulletin in mental health

Encourage the establishment of collaborative linkages and we shall strive to ensure that exchange visits take place within the limits of our financial well-being

Improve the quality of teaching at the department through the production and/or acquisition of sultable learning materials. A book on epilepsy has already been published and it is hoped that this will boost the image of the department in the university and improve the quality of care provided to individuals with epilepsy in the future

the institution of health promotional measures at the university. The department is one of the centres for a World Health Organization (WHO) project investigating the psychosocial aspects of onchocerciasis (river blindness disease), a filarial infection of the skin. Four studies on onchocerciasis have helped to highlight the public health importance of the disease in sub-Saharan Africa and a treatment regimen for the treatment of onchoceral skin disease has since been determined and adopted by the African Programme for Onchocerciasis Control (APOC).

\section{Psychiatry in Uganda}

The first psychiatric service in Uganda began to operate in 1924 from a government prison at Hoima, central Uganda. The first psychiatric hospital was later built on Mulago Hill in Kampala in 1945 and this was followed by the establishment of Butabika Hospital, located $16 \mathrm{~km}$ outside of Kampala, which is now the only psychiatric hospital in Uganda. Butabika Hospital is situated in $1 \mathrm{~km}^{2}$ of attractive grounds and has between 350 and 400 beds, which have been reduced from a peak of 750 . In addition there is a 40-bedded psychiatric admission ward adjacent to the department of psychiatry which is in a state of poor repair and is now rarely full. Out-patient clinics, which are also in disrepair, are located behind the medical school. The out-patient department handled
7500-9000 attendances each year between 1994 and 1996 and between 1500 and 2000 of these were admitted to Butabika Hospital. The department and its associated out-patient and in-patient units are to move to Butabika this year to allow repairs to be carried out.

As in many countries in the developing world the policy is for mental health services to be integrated into general health care and this is one of 10 components of primary health care in Uganda. The village health worker is expected to recognise neuropsychiatric disorders and to refer for appropriate treatment. To assist in this many nurses will undergo a 'Comprehensive Nursing Course' in which they receive training in mental health, paediatrics, obstetrics, general medicine and surgery to equip them to work in primarycare settings. There are only nine senior psychiatrists and two trainees currently working in Uganda. In addition, a visiting psychiatrist from Holland works in the Mbarara District, about $270 \mathrm{~km}$ west of Kampala, and covers a population of about 850000 . The lack of fully trained psychiatrists is supplemented by the use of general duty medical officers, who have received general medical training, and psychiatric clinical officers (PCOs). The PCOs are highly regarded personnel who are not medically trained but who have received a two-year training programme at Butabika Hospital in practical and theoretical aspects of psychiatry. Their role is to diagnose and treat (including prescribing) mental disorders. The PCOs form an important part of the 
future of psychiatric services in Uganda, as the intention is that psychiatrists will be based at the main regional hospitals and PCOs will provide input at the district level down to health centres. At present there are too few psychiatrists and PCOs to achieve this and the PCOs are situated at regional hospitals which the psychiatrists do not visit.

Diagnostic facilities and psychiatric treatments are limited. Neither Butabika nor the Department of Psychiatry have electroencephalogram (EEG) facilities despite seeing a large proportion of seizure disorders. Electroconvulsive therapy (ECT) is used but given in an unmodified form. The formulary is restricted, although many of the common neuroleptic drugs are available. There are limited opportunities to use psychological treatments. The outcome for many disorders is unknown. As most of the services are centralised in Kampala it is difficult for much of the population to receive appropriate and comprehensive mental health care and follow-up of individuals is mainly incomplete.

The case histories outlined in this paper show the breadth of clinical problems encountered. The effects of AIDS in Africa are seen by psychiatric services, as are the effects of infectious diseases and malnutrition. Epilepsy is commonly seen in primary-care clinics and hospitals but is often not adequately treated. Psychiatrists are aware of the increasing substance misuse problem but do not have the facilities to treat it. One consequence of military violence and of being involved in a protracted war in which nearly all Ugandan families lost one member and many civilians were tortured and mutilated is a high prevalence of post-traumatic stress disorder (PTSD). Supplementing this is the drift of refugees from surrounding countries such as the Sudan and Rwanda, who have suffered similar privations.

Psychiatrists in Uganda are actively involved in assisting in projects to treat and rehabilitate these sufferers and are also involved in a nongovernmental organisation project, 'Hope after Rape'. Members of the Department of Psychiatry have been responsible for bringing to public attention the problems of substance misuse and child abuse and neglect through newspaper articles and radio broadcasts.

\section{Case histories}

\section{Subdural haematoma}

Patrick, a 30-year-old welder, presented to a PCO following a convulsion three days earlier. Patrick recovered from the convulsive episode with residual paresis of the right limbs. Mental state assessment revealed mild stupor, disorientation to time, poor concentration, poor memory for personal events, sluggish thought process, and vague expression of ideas. Patrick had been involved in a bicycle accident 12 years earlier and had fallen off a motor cycle seven years ago, although there was no clear evidence as to whether Patrick lost consciousness on either of these two occasions. Patrick has four children, three of whom suffered from convulsions, and a fourth child suffered from sickle cell disease. Patrick was transferred to Kampala for further investigation and an EEG revealed frequent runs of sharp, slow waves in short runs over the left hemisphere with phase reversal over the left temporal area spreading centrally and occipitally. Computed tomography demonstrated the presence of a semi-lunar shaped chronic epidural haematoma in the left fronto-parietal region measuring $14 \mathrm{~mm}$ at its widest diameter. There was left-to-right shift of the midline of $4.5 \mathrm{~mm}$. In this case a few relevant investigations helped to identify the curable cause of convulsions. However, in Uganda adequate clinical management often depends on the elicitation of clinical signs and symptoms alone as sophisticated modern technology is not available to many practitioners.

\section{Probable schizophrenia}

Mr M. a 36-year-old teacher from northern Uganda, complained of being worried, restless and physically exhausted for three years. In addition, he experienced pain in his neck. felt sleepy at any time, was forgetful, felt dizzy and experienced false sexual arousal but could not sustain erections. He suffered from auditory hallucinations in the form of a running commentary on his activities. Mr M. believed that there was a machine in the home of the Area District Commissioner that was being used to monitor his movements, broadcast his thoughts and conversations with people, and to make life generally difficult for him. He complained that his limbs were being controlled by the machine, and that: 'Some people have specialised in making me suffer, smile, become serious ... . It is all directed and governmentsponsored ... My movements and activities are monitored. I have no privacy ... The machine reads what I read, repeats what I do. I have no time. All the time I am under the influence of the machine. I do not know the eventual aim of these people . . . Even this interview is being recorded and transmitted elsewhere. Everything I do is recorded. When I am in the toilet, they burst out laughing ... Mr M. experienced thought withdrawal, he believed that his ideas were being used by his enemies for their own (political) gains and complained of the experience of nauseating olfactory hallucinations. He was started on chlorpromazine and asked to return for an EEG examination. He never returned as he lacked money for the examination and came from the Lira district $300 \mathrm{~km}$ from Kampala.

\section{Affective disorder with obsessional symptoms}

Eugene, a 15-year-old builder, complained that over a period of four years he had been confused with numerous and repeated worries and thoughts that ran through his mind against his wishes. In addition 
he experienced vivid images of his thoughts and worries almost simultaneously. These symptoms had forced him to abandon his building work, and made it difficult for him to cross roads safely because he often got involved with the worries to the point of not being aware of his surroundings. The thoughts and worries assumed the form: 'Maybe a motor accident has taken place at Jinja or Masaka . . . Maybe someone has died ... Maybe a relative is seriously sick ... Maybe someone's house has caught fire . . . Maybe someone has been shot at ... His sleep was poor and he often woke up unrefreshed from sleep in the mornings. His appetite was reduced and he had experienced episodes of vomiting over the three weeks preceding the consultation. For as long as he could recall Eugene had experienced episodes of weakness alternating with episodes of transient but increased energy, when he also felt extremely happy. elated and excited. Episodes of weakness were associated with feeling depressed as if I have lost someone'. He had experienced suicidal thoughts over one year and he attempted to kill himself with rat poison two weeks before consultation. In his depressed state Eugene felt there was no future for him. that the sickness might kill him anytime. In addition, he felt worthless: What is my use when I cannot understand properly? The head is spoilt'. He felt ashamed of himself over trivial failures on his part, 'such as when I switch on the television set and it does not work, or when I greet someone who does not answer me because I might have spoken softly'. Eugene was illegitimate and he currently lived with his maternal grandmother. His father, who worked as a truck driver, drank heavily and spared no money for Eugene's education. The father had no other child with his current wife and his mother, who lived on her own, had four other children with three different men. Eugene dropped out of school after only four years of primary education and became a builder in order to support himself. A maternal uncle of the same age as Eugene had attempted suicide by poisoning two weeks before Eugene tried to kill himself. Eugene believed that the worries, thoughts and images were part of himself and he felt that there was no pleasure in experiencing them: He believed that it was better to die and forget the problems of this world. He was given amitriptyline and reported improvement when he returned four weeks later.

\section{Probable postnatal brain damage}

John. a ten-year-old only son of a secretary, presented with progressive loss of skills he had previously acquired. John had been a normal healthy baby delivered by caesarean section due to cephalopelvic disproportion. His development up to four years of age had been uneventful, and he attained above average grades at nursery school. However, by the age of four years John had started to lose the skills he had previously acquired. He had lost skills for personal care and he could no longer dress himself. His judgement was poor, he was impulsive and was in constant danger of injury. His attention was difficult to draw and sustain. He could not readily respond to verbal commands. His speech was limited to repetitive monosyllables like: 'Bye Bye Ba' or 'Pair Pair'. He seemed to have special interest in music and he often sang to himself in monosyllables. In dim light he could not find his way round in the family house as his vision was impaired. A year before he was brought for consultation he had stopped going to the toilet and would laugh whenever he wanted to open his bowels or urinate. There was history of febrile convulsions but he had not had any convulsive episode since he became ill. John had been immunised against measles, tuberculosis, tetanus, diphtheria, poliomyelitis, and whooping cough. Biochemical tests for heavy metal poisoning and metabolic errors could not be done due to lack of reagents. The Treponema pallidum haemagglutination test for syphilis was negative. The EEG record showed constant slow wave focus in both pre-central areas, accompanied by tiny spikes and sharp waves. particularly in the right anterior area. Computed tomography of the brain showed cerebral atrophy secondary to degenerative process which could be due to sub-acute sclerosing panencephalitis. John's mental state improved slightly on a course of ethosuximide $250 \mathrm{mg}$ daily. His attention could be sustained, he was able to follow verbal instructions and he was less impulsive in behaviour.

\section{Obsessive-compulsive disorder}

Rita, a 21-year-old school teacher, presented with obsessional ruminations of four months duration. The ruminations took the form of: Why does everyone have two legs or two eyes? Why do people die? Why were we born? ... $\therefore$ Rita complained that she did not understand herself or who she really was. She experienced associated heat in the centre of the head. She slept poorly and often woke up with the ruminations which interfered with her work. Rita experienced no hallucinations, passivity phenomena, delusions, depressive symptoms, or epilepsy. There was no family history of similar illness. Her problem had been going on for an unspecified period of time but was aggravated by a disagreement with a tenant of her mother over house rent. Rita had feared that the tenant would bewitch her so that she would die. Her father had died when she was aged nine years. Her mother was still alive and she worked as a nurse. Rita had one stepbrother who was two years older than herself. Rita was given imipramine with good results and was able to return to full-time employment.

\section{Post-traumatic stress disorder}

Sarah was a 24-year-old university student from Northern Uganda. She complained of auditory and visual hallucinations. Her sleep was frequently interrupted by nightmares involving soldiers chasing people, a boy grabbing her by the face, or a girl stabbing her with a knife. Sarah felt sad and complained that she was failing in her studies, that she was disappointing her father, that she lacked emotional attachment and that her friends complained that her character had changed. She was irritable over trivial matters and often became aggressive towards others without caring about the consequences of her behaviour. Sarah felt suicidal 
and planned to poison herself, or provoke someone to murder her. She had been abducted along with other students from her school by rebels five years earlier but had never received help after this experience. She improved on chlorpromazine combined with counselling.

\section{Current problems}

Many of the problems facing Ugandan psychiatry are familiar to all parts of the world, those of the low status of psychiatry and lack of resources. There are few psychiatrists in Uganda and probably only five Ugandan trained psychiatrists working abroad. Recruitment to the speciality of psychiatry is difficult owing largely to its low status and poor pay (a trainee psychiatrist earns USh90 000-about $\$ 60$ per month) and senior psychiatrists have to supplement their salary with extra work. Recruitment of social and behavioural scientists and clinical psychologists is also problematic and it is thus difficult to employ sufficient numbers of experienced clinicians, teachers and researchers to head necessary developments. The consequences of this are not only that training of personnel is slow but also that there is little adequate research by which service developments can be directed.

The Mental Treatment Act for Uganda is in need of revision. The current act dates back to 1938 and was last revised in 1962. The act involves a tedious process of certification which requires the signature of two medical officers and a magistrate and it lasts for one year, or until rescinded by a magistrate. There are urgency orders which allow for admission until a reception order can be completed. In practice the Mental Treatment Act is not well adhered to; most psychiatric admissions are for less than four weeks and up to half of the admissions to Butabika Hospital are voluntary, usually at the request of a relative or a self-referral. Patients are rarely reviewed by a magistrate and while there is provision for review tribunals these seldom occur. It seems that for the bulk of psychiatric patients in Uganda the act no longer applies.

In addition to the lack of personnel via which treatments can be directed across the country there are a lack of available treatments. There is a need to examine the formulary of drugs and to inspect the practice of ECT. While provision for psychological treatments is poor it is uncertain as to whether these treatments would be acceptable to the ordinary Ugandan patient as many do not accept the need for such treatments and are not satisfied until some medication has been prescribed. The use of traditional healers, both instead of and in addition to medical services, is common and there is a trend for the Ugandan government to recognise the value of such healers and to encourage liaison between them and the medical services particularly in primary care.

\section{AIDS and mental health in Uganda}

The problem of AIDS cuts across the frontiers of many professions. It has been estimated that half a million Ugandans have died of AIDS since the disease was first diagnosed in the Rakal district in 1982 and one and a half million people are estimated to be infected with HIV. Recently the Ministry of Health announced that the number of people infected with the AIDS virus has fallen in the major towns but in the rural areas it has risen by $10 \%$. Many individuals die in agony, having no access to professional help. Some families are headed by children with both parents having died of AIDS. In Mulago Hospital, the national teaching and referral general hospital, $60-80 \%$ of medical beds can be occupied by people suffering from AIDS-related physical disorders, commonly tuberculosis, at any one time. In Butabika mental hospital 20-24\% of the patients are HIV-positive. Despite these figures few patients receive professional counselling from the health professionals.

Patients with AIDS-related disorders present in many ways to the Ugandan psychiatrist including affective disorders, acute confusional states, dementia, and anxiety states in the form of persistent and morbid fear or worry about infection with HIV despite evidence to the contrary (see AIDS-related case histories). Persons suffering from AIDS are concerned over issues of guilt, shame, personal reputation, fear of death, fear of being abandoned by relatives and friends, their ambitions and other unfinished business, and the welfare of survivors. Episodes of physical illness associated with AIDS are extremely debilitating. A diagnosis of AIDS puts a rude end to future plans, disrupts social structure and order within families, and poses a formidable crisis for affected individuals and their families.

\section{AlDS-related case histories}

\section{Case 1}

Dr B., a young surgical trainee, was referred for counselling following a serious attempt at selfpoisoning. He wept profusely when giving the history of his suicide attempt, pouring scorn on himself for contracting AIDS. Dr B. was an only son, brought up by his mother to whom he felt indebted. When the AIDS epidemic erupted he took precautions to avoid the disease by abstaining from casual sexual contact so that he could fulfil his wishes of rewarding his mother for her troubles in raising him through succeeding in his medical education. He believed 
that he contracted the disease from his only sexual partner, a woman he later hoped to marry. He blamed himself for contracting AIDS, for letting his mother down, and for failing to fulfil his ambitions. He worried about his personal property which he had acquired since his graduation from medical school. The early signs of infection were dermatological and he felt ashamed of his appearance. He began to seclude himself and would not entertain the idea of visits, even from his closest friends. He tried to kill himself to escape the shame and pain of death.

\section{Case 2}

A. B., a university academic, presented when physically ill with a fungal skin infection. The initial reason for presentation was unclear but after two weeks his mental and physical state deteriorated. He believed that his work colleagues had conspired to kill him and that he had been appointed as Ambassador to Khartoum. He demanded that the psychiatrist help him get his papers in order and make arrangements for his flight. This state responded to treatment with neuroleptics but as he recovered it became apparent that his daughters showed little respect for their father and his wife was indifferent to his state. He clung to the psychiatrist. wishing him to be at his side at all times. It emerged that his marital relationship had been poor for many years and that he wished reconciliation with his wife. There had been no sexual relationship for a considerable period and he had an extramarital affair with a woman who had died of an AIDS-related disorder two years earlier. A. B.'s son had died of an AIDS-related illness six months earlier.

\section{Case 3}

P. M., a man of 30, first presented with impotence in the context of marital conflict relating to heavy drinking and physical violence. He had an affair with a woman whose husband died of AIDS and consequently his wife refused to have sexual intercourse with him. Two years later P. M. presented emaciated and with a febrile illness. He had become irritable. restless, overactive, preoccupied with lavish plans, was sleeping poorly and spending money. Screening revealed him to be HIV-positive. He exhibited impaired concentration, disorientation, slow and effortful intellectual activity and impaired short-term memory. He had episodes of anxiety, agitation and apprehension and believed that the knowledge of having AIDS would kill him faster than he wished. His physical condition was poor, he suffered from pulmonary tuberculosis, frequent gum bleeding as a result of gingivitis and his hair had turned silky. During his illness his elder brother and younger sister died of AIDS within one week of each other. At one stage he presented the physicians with a dilemma when he asked if he could resume sexual intercourse with his wife. P. M. died after a long illness and his wife was later confirmed as being HIVpositive.

\section{Case 4}

M. A., a 24-year-old Asian accountant, had come to Uganda from southern India to earn a living five months previously at the request of his family. Four weeks before his referral he had engaged in his first ever sexual experience. During intercourse, with a Ugandan woman with whom he worked, the condom burst. He washed vigorously but became convinced that he was infected with the AIDS virus although there was no clinical evidence that this was so. He became anxious, worried, depressed and felt warm waves pass periodically over his body. His appetite reduced and his sleep became disturbed. He lost interest in his hobbies and could not concentrate at work. He blamed himself for catching the AIDS virus and felt guilty that he had let his family down. Although he lived closely with his Asian friends and colleagues in Kampala he could not disclose the nature of his problem to them and he was preoccupied with the thought that he could not return to India as he felt his family would reject him and not forgive him for contracting AIDS. He experienced recurrent suicidal thoughts and had several episodes of self-poisoning.

\section{Overview}

Governments and health organisations across the world are becoming increasingly aware of the public health challenge of mental disorders (Desjarlais et al, 1995) and the World Bank Report in 1993 estimated that mental health problems the world over produce $8.1 \%$ of the Global Burden of Disease, a toll greater than that exacted by tuberculosis, cancer or heart disease. Worldwide, however, there remains the stigma of mental illness and a resistance for authorities to place emphasis or priority on addressing the suffering caused by it. The situation in Uganda is no exception to this and has been exacerbated in the past by the excesses of war and political and economic instability from which, in recent years, Uganda has tried to rebuild itself. The academic department of psychiatry at Makerere and psychiatric services in Uganda began promisingly but suffered the same fate as the country as a whole; nevertheless they too are re-emerging and revitalising themselves. They do have a long way to go and have to face the added burdens of a high prevalence of AIDS and PTSD.

In its efforts to rebuild psychiatry in Uganda, the department at Makerere will need political support and increased funding by government. The development of links with local agencies and institutions has begun and local interest in research is being encouraged as one strategy to sustain the debate for needs and improve standards. This paper was written after a visit by J. B. to Uganda, one of a series of exchange visits between the departments of psychiatry at Keele and Makerere Universities. It is hoped that 
the liaison between the two departments will benefit both the UK and Uganda and contribute to the closing of the gap that exists between need and provision of mental health services in one East African country.

\section{Acknowledgements}

The authors are grateful to the Tropical Health Education Trust, Professor Eldryd Parry and Professor John Ssebuwufu, Vice Chancellor of Makerere University for financing and facilitating the visit of J. B. to Uganda.

\section{References}

Cox, J. L. (1983) Post-natal depression: A comparison of African and Scottish women. Social Psychiatry, 18, 2528.

Desuarlais, R., EISENBERG, L., GoOD, B., et al (1995) World Mental Health Problems and Priorities in Low-Income Countries. Oxford: Oxford University Press.
German, A. \& ARYA, O. P. (1969) Psychiatric morbidity amongst a Ugandan student population. British Journal of Psychiatry, 115, 1323-1329.

ODONGA. A. M. (1989) The First Fyty Years of Makerere Medical School and the Foundation of Sctentific Medical Education in East Africa. Kampala: Marlanum Press.

ORLEY, J. H. (1970) Culture and Mental Illness: A Study From Uganda. Nairobi: East Africa Publishing House.

- . Wing, J. K. (1979) Psychiatric disorders in two African villages. Archives of General Psychiatry, 36, 513-520.

WORLD BANK (1993) World Development Report, 1993: Investing in Health. New York: Oxford University Press.

*Jed Boardman, MRCPsych, Senior Lecturer in Social Psychiatry, Academic Department of Psychiatry, School of Postgraduate Medicine. Keele University. Thomburrow Drive, Stoke-onTrent, Staffordshire ST4 7QB and Emilio Ovuga, MMedPsych, Head of Department of Psychiatry. Makerere University, Kampala, Uganda

*Correspondence 